\title{
Keterkaitan Kualitas Air dengan Keanekaragaman Zooplankton di Sungai Barito Marabahan Kabupaten Barito Kuala
}

\author{
Dini Sofarini ${ }^{1^{*}}$, Siti Aminah ${ }^{2}$, Rina Nur Hidayah ${ }^{1}$, Marissa Septa Hanifa ${ }^{1}$ \\ ${ }^{1}$ Prodi Manajemen Sumberdaya Perairan Fakultas Perikanan dan Kelautan \\ ${ }^{2}$ Prodi Perikanan Tangkap Fakultas Perikanan dan Kelautan \\ Universitas Lambung Mangkurat \\ Jl. Brigjend Hasan Basri Pangeran Kota Banjarmasin 70123 Kalimantan Selatan \\ *dina.sofarini@ulm.ac.id \\ DOI: https://doi.org/10.21107/rekayasa.v14i3.12340
}

\begin{abstract}
The fish diversity in Barito River is determined by diversity of zooplankton, in relation to the grazing food chain's concept. One of the problems that occur is the quality of several key parameters in waters are no longer suitable for zooplankton and fish life. The purpose of this research were: (a) analyze the key parameters of water quality at the sampling location (b) determine the relationship between key water quality parameters and zooplankton diversity at the Barito River sampling location. The method used was a purposive sampling survey method and the shanon-wiener method. The results showed that the key parameters that met the PP No. 22/2021 Water Quality Standard for Class 2 River Water Quality.
\end{abstract}

Key words : zooplankton, Barito river, diversity, water quality

\section{PENDAHULUAN}

Sungai Barito adalah sungai yang berhulu di Pegunungan Schwaner di Propinsi Kalimantan Tengah, memasuki Kota Marabahan di Propinsi Kalimantan Selatan, hingga bermuara di Laut (Rupawan, 2017). Sungai Barito ini merupakan salah satu sungai dataran rendah yang terpanjang di Kalimantan Selatan, yaitu mencapai 909 kilometer, dengan lebar sungai 650-800 meter dan kedalaman rata-rata 8 meter. Lebar sungai pada bagian muara yang berbentuk corong mencapai 1.000 meter, sehingga Sungai Barito merupakan sungai terlebar di Indonesia.

Kalimantan Selatan termasuk ke dalam wilayah kepulauan bercirikan sejumlah besar sistem sungai dataran rendah, yang mengalir dari daerah pedalaman ke lautan. Menurut Hall (1985), keadaan seperti itu merupakan sebuah keistimewaan yang membawa pengaruh signifikan terhadap perkembangan sosial dan ekonomi daerah bersangkutan. Dari waktu ke waktu

\section{Article History:}

Received: August, 30 ${ }^{\text {th }}$ 2021; Accepted: November, $27^{\text {th }} 2021$ Rekayasa ISSN: 2502-5325 has been Accredited by Ristekdikti (Arjuna) Decree: No. 23/E/KPT/2019 August 8th, 2019 effective until 2023 masyarakat bermukim di antara berbagai sistem sungai itu, sehingga terjadi konsentrasi penduduk di daerah delta yang luas di mulut sungai.

Sungai Barito merupakan daerah yang juga dimanfaatkan oleh masyarakat sebagai daerah penangkapan ikan (fishing ground) dan kegiatan budidaya ikan sistem Karamba Jaring Apung (KJA) (Rudini et al., 2018; Rupawan, 2017). Perairan sungai, termasuk Sungai Barito, memiliki peran ekologis yang antara lain berupa sumber zat hara dari bahan organik yang diangkut oleh arus air, tempat pemijahan, asuhan dan tempat mencari makan. Selain itu pula, memiliki peran penting secara ekonomi sebagai lahan usaha perikanan tangkap dan budidaya, sumber pendapatan dan sumber protein hewani (Rupawan, 2017). Sungai Barito memiliki biota perairan yang kompleks dan beragam, dimana hampir di semua daerah perairan terdapat berbagai jenis plankton, ikan, dan organisme perairan lainnya dan

\section{Cite this as:}

Sofarini, D., Aminah, S., Hidayah, R.N \& Hanifa, S.M. (2021). Keterkaitan Kualitas Air dengan Keanekaragaman Zooplankton di Sungai Barito Marabahan Kabupaten Barito Kuala. Rekayasa 14 (3). 421-430 doi: https://doi.org/10.21107/rekayasa.v14i3.12340.

(C) 2021 Dina Sofarin 
keberadaannya dapat diamati secara langsung maupun melalui mikroskop. Dewasa ini di Sungai Barito ada kecenderungan bahwa kondisi kualitas air mengalami penurunan. Hal ini disebabkan oleh pengaruh intrusi air laut, pencemaran air dari limbah domestik dan aktivitas lalu lintas angkutan batubara melalui perairan Sungai Barito (Rudini et al., 2018)).

Keberadaan KJA di sepanjang Sungai Barito juga akan berdampak pada kualitas perairannya. Kualitas perairan ini untuk selanjutnya akan mempengaruhi perkembangan organisme perairan secara berlebihan. Hal ini merupakan gangguan dan dapat dikategorikan sebagai pencemaran, yang dapat merugikan organisme akuatik lainnya maupun manusia secara tidak langsung melalui konsep food web. Air dikatakan tercemar apabila ada pengaruh atau kontaminasi zat organik maupun anorganik ke dalam air. Peningkatan jumlah trace element (beban pencemar) tersebut mengakibatkan terganggunya kestabilan parameter kualitas perairan, terutama parameter kualitas air kunci perairan sungai. Peningkatan konsentrasi nutrien yang berkelanjutan dalam badan air dalam jumlah besar sehingga badan air menjadi eutrofik dan menstimulan blooming berupa kondisi eutrofikasi dan defisit konsentrasi oksigen terlarut (Arifin et al., 2016). Senyawa beracun yang menjadi tempat hidup mikroba berakibat pada degradasi biota perairan termasuk zooplankton dan sumberdaya ikan, bahkan kematian serta penyusutan debit air. Zooplankton pada konsep food chain menempati posisi sebagai konsumen tingkat 1 yang mengkonsumsi fitoplankton. Ikan-ikan pemakan zooplankton menempati urutan berikutnya, sebagai konsumen tingkat 2.

Peningkatan limbah cair di perairan tidak terlepas dari kebiasaan/prilaku masyarakat untuk membuang semua aktivitas mandi cuci kakus, limbah dapur, botol/wadah pestisida ke perairan karena mudah dan belum ada fasilitas untuk pengelolaan limbah tersebut. Selama ini asumsi orang membuang limbah cair domestik ke badan air karena menganggap bahwa air dapat melakukan daur ulang limbah cair secara fisika, kimiawi dan biologi berupa pelarutan hampir semua jenis zat/bahan (Suprihatin, 2014). Rendahnya tingkat kesejahteraan, lapangan kerja, kemiskinan dan tingkat pendidikan menyebabkan terbiasanya masyarakat utnuk membuang limbah ke perairan. Hal ini berdampak pada penurunan kualitas perairan dan biota air yang hidup didalamya, termasuk zooplankton dan ikan, sehingga terjadi penurunan hasil tangkapan ikan. Keterkaitan kualitas air dengan keanekaragaman zooplankton di Sungai Barito belum diketahui secara jelas. Oleh karena itu perlu dilakukan penelitian untuk mengetahuinya, sehingga dapat diketahui data kualitas air, keanekaragaman zooplankton dan ikan di perairan Sungai Barito. Hal ini bermanfaat sebagai informasi bagi para pengambil kebijakan untuk mewujudkan pemanfaatan Sungai Barito ke depan untuk dijadikan kawasan yang ramah lingkungan, baik untuk kegiatan penangkapan ikan dan budidaya.

Kualitas perairan merupakan hal yang terpenting bagi kehidupan dan produktivitas di perairan tersebut. Sebagai faktor biologi, biota air yang hidup didalamnya, tergantung pada faktor fisik kimia kualitas air agar kondisi kehidupan perairan tetap berjalan dengan stabil. Gangguan yang terjadi di suatu perairan akan mempengaruhi faktor fisik kimia kualitas air terlebih dahulu, baru kemudian berdampak lanjutan pada biota air. Merunut pada konsep rantai makanan rerumputan (grazing food chain), gangguan pada faktor fisik kimia tersebut akan berimbas dampak lanjutan pada tingkat trofik selanjutnya (Muhtadi, 2017).

Gangguan pada badan air, berupa masukan bahan organik yang terbawa melalui limbah yang dihasilkan oleh kegiatan manusia maupun sisa aktivitas biota air akan masuk ke perairan. Pada kondisi tertentu hal ini akan mengganggu kondisi existing perairan. Zooplankton yang menempati tingkat trofik kedua pada konsep rantai makanan (konsumen tingkat 1) akan dipengaruhi oleh kondisi kualitas air yang terganggu tersebut. Pada tingkat trofik selanjutnya, ikan pemakan plankton di posisi konsumen tingkat 2 juga akan dipengaruhi baik oleh kondisi kualitas perairan maupun dari indeks kelimpahan dan keanekaragaman zooplankton sebagi sumber makanannya (Sofarini et al., 2020)

Sungai Barito memiliki biota perairan yang kompleks dan beragam dimana terdapat berbagai jenis ikan, plankton dan organisme perairan lainnya yang keberadaannya dapat diamati secara langsung. Dewasa ini di Sungai Barito ada kecenderungan bahwa kondisi kualitas air mengalami penurunan. Hal ini disebabkan oleh pengaruh intrusi air laut, pencemaran air dari limbah domestik dan aktivitas lalu lintas angkutan batubara melalui perairan Sungai Barito (Rudini et 
al., 2018). Hal ini menggambarkan kondisi perairan yang juga mengindikasikan kerusakan kualitas air, produktivitas perairan dan lingkungan perairan secara keseluruhan. Penurunan populasi disebabkan adanya gangguan pada sistem ekologi dan ada 6 kategori utama menurunnya keanekaragaman ikan air tawar yaitu perubahan habitat, eksplorasi yang berlebihan, introduksi ikan asing, pencemaran, perubahan kualitas air, dan pemanasan global (Wargasasmita, 2005). Perubahan habitat (25\%) dan introduksi ikan asing (30\%) sebagai faktor utama menurunnya populasi ikan air tawar (Sofarini et al., 2018).

Penelitian ini memberikan luaran berupa data kualitas air, keanekaragaman zooplankton dan ikan di perairan Sungai Barito. Hal ini bermanfaat sebagai informasi bagi para pengambil kebijakan untuk mewujudkan pemanfaatan Sungai Barito ke depan untuk dijadikan kawasan yang ramah lingkungan, baik untuk kegiatan penangkapan ikan dan budidaya perikanan. Tujuan penelitian ini adalah untuk menganalisis parameter kunci kualitas air di lokasi sampling dan mengetahui keterkaitan parameter kunci kualitas air dengan keanekaragaman zooplankton di lokasi sampling Sungai Barito.

\section{METODE PENELITIAN}

Penelitian ini dilaksanakan selama 6 bulan di perairan Sungai Barito Kecamatan Marabahan Kabupaten Barito Kuala Provinsi Kalimantan Selatan. Kegiatan sampling dilakukan selama dua kali dengan selang waktu tiga minggu. Penentuan lokasi sampling ditentukan secara purposive, di dua lokasi yaitu kawasan hulu dan hilir perairan.

Pengambilan sampel kualitas air dilakukan di lokasi yang sama dengan pengambilan sampel zooplankton, yaitu di lokasi yang dianggap mewakili perairan Sungai Barito di daerah hulu dan hilir. Parameter kualitas air yang diambil adalah BOD dan TSS, yang dianalisa di Laboratorium Kualitas Air dan Hidro-Bioekologi dengan metode spektrofotometri, serta DO, pH dan suhu yang dianalisa secara insitu di lokasi sampling. Sampel zooplankton dibawa ke Laboratorium Kualitas Air dan Hidro-Bioekologi untuk diamati dibawah mikroskop. Perhitungan Indeks Zooplankton adalah sebagai berikut :
- Abundance Index (Metode Hardy)

$$
\mathrm{N}=\frac{\mathrm{n}}{\mathrm{m}} \mathrm{x}_{\frac{\mathrm{a}}{\mathrm{a}}}^{\mathrm{s}} \mathrm{x}_{-}
$$

Keterangan :

$\mathrm{N}=$ Indeks Kelimpahan (sel/lt)

$\mathrm{n}=$ Jumlah individu spesies ke-i (sel/lt)

$\mathrm{m}=$ Jumlah tetes sampel yang diperiksa

$\mathrm{s}=$ Volume sampel dengan pengawet $(\mathrm{ml})$

$a=$ Volume tetes air sampel $(\mathrm{ml})$

$\mathrm{v}=$ Volume air yang disaring

- Diversity Index (Metode Shannon-Winner)

$$
H^{\prime}=-\Sigma_{N}^{n i}-\log _{N}^{n i}-
$$

Keterangan :

$$
\begin{aligned}
& \mathrm{H}^{\prime}=\text { Indeks Keanekaragaman } \\
& \mathrm{N}=\text { Indeks Kelimpahan (sel/lt) } \\
& \mathrm{n}=\text { Jumlah individu spesies ke-i (sel/lt) }
\end{aligned}
$$

$$
\begin{aligned}
& \text { - Dominance Index (Metode Shannon-Winner) } \\
& \qquad \mathrm{C}=\Sigma \frac{\mathrm{ni}^{2}}{\mathrm{~N}}
\end{aligned}
$$

Pengambilan sampel ikan dengan menggunakan alat tangkap gill net selama waktu tertentu, untuk memperoleh gambaran kualitatif kondisi perikanan secara in situ, baik ikan ekonomis atau ikan non-ekonomis. Ikan-ikan yang tertangkap kemudian diidentifikasi di lapangan berdasarkan buku identifikasi ikan. Jika tidak memungkinkan, maka sampel ikan diberi larutan formalin untuk diawetkan dan dimasukkan ke kantong plastik untuk diidentifikasi di Laboratorium Iktiologi Fakultas Perikanan dan Kelautan ULM. Informasi data sekunder dilakukan dengan data dari Dinas Ketahanan Pangan dan Perikanan Kabupaten Barito Kuala.

\section{HASIL DAN PEMBAHASAN \\ Dissolved Oxygen (DO)}

Konsentrasi oksigen terlarut (DO) yang diperoleh dari hasil analisa yang tertera pada Tabel 1 dan Gambar 1 berada pada kisaran 2,3 - 5,1 $\mathrm{mg} / \mathrm{L}$. Ini merupakan kisaran nilai DO yang agak rendah hingga bagus, mengingat perairan sungai mengalami pertukaran oksigen dari arus air yang mengalir hulu ke hilir (Suratman et al., 2006). Nilai tertinggi, yang sesuai dengan batas minimal nilai 
DO di perairan yaitu $4 \mathrm{mg} / \mathrm{l}$ (Peraturan Pemerintah No 22 Tahun 2021 Tentang Penyelenggaraan Perlindungan dan Pengelolaan Lingkungan Hidup, 2021). Nilai ini diperoleh pada Stasiun 1 Ulu Banteng sampling 1 . Nilai yang terendah, jauh dibawah batas minimal nilai DO, yaitu $2,3 \mathrm{mg} / \mathrm{l}$, berada pada Stasiun 2 Rumpiang sampling 2 (Gambar 1).

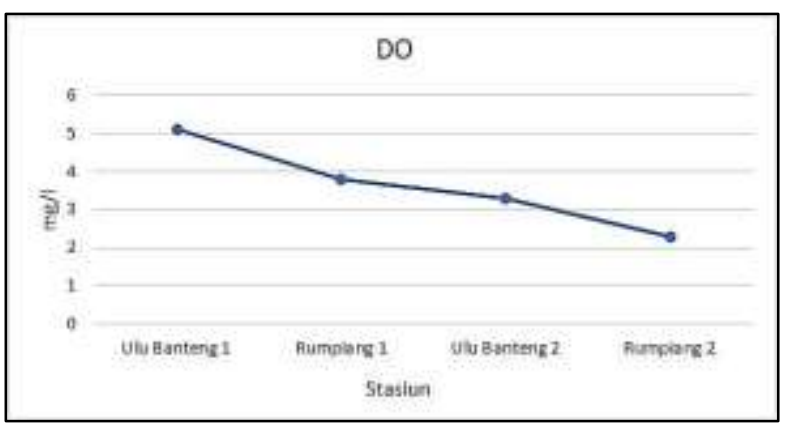

Gambar 1. Nilai DO (mg/l) pada Setiap Stasiun

Pengamatan dari 2 Kali Pengambilan Sampel

Hasil pengukuran DO pada penelitian ini lebih tinggi daripada hasil pengukuran DO pada penelitian Lavabetha et al (2015) di Muara Sungai Barito Kabupaten Barito Kuala, yang menunjukkan nilai DO dengan kisaran yang rendah, yaitu 0,37 3,77 mg/l. Sedangkan hasil penelitian di Muara Sungai Barito Kabupaten Barito Kuala, yang diteliti oleh Dwiyitno et al (2008), dimana kisaran DO yang didapatkan cukup tinggi dan sesuai dengan baku mutu air, yaitu sebesar 3,0 - 4,8 mg/l.

Suatu perairan dikatakan baik jika tingkat pencemaran rendah dengan DO lebih besar dari 5 mg/L (Wanna et al., 2017). Menurut (Wanna et al., 2017) kadar oksigen terlarut dalam perairan alami biasanya kurang dari $10 \mathrm{mg} / \mathrm{L}$. Kadar oksigen terlarut pada air di kawasan Sungai Barito pada penelitian ini beragam, dari dibawah baku mutu air hingga diatas baku mutu air kriteria PP No 22 Tahun 2021 untuk air sugai dan sejenisnya (Kelas 2). Sungai Barito memiliki arus aliran air yang kuat/lancar jika dilihat secara kasat mata. Menurut penelitian (Wanna et al., 2017) tingginya nilai oksigen terlarut disebabkan tingginya gerakan air/arus. Selain itu banyaknya tumbuhan liar di lokasi penelitian menjadikan perairan kaya kandungan oksigen terlarut. Effendi (2016), menambahkan bahwa sumber utama oksigen di perairan berasal dari aktivitas fotosintesis oleh tumbuhan air. Proses pengadukan air pada perairan sungai seringkali terjadi, entah karena arus atau angin. Pengaruh limpasan air yang menyebabkan perairan mengalami pengadukan juga dapat terjadi.

Nilai oksigen terlarut yang dibawah baku mutu air dapat disebabkan oleh proses dekomposisi bahan organik. Proses ini disebabkan oleh aktivitas bakteri aerob yang terus terjadi, dimana sumber bahan organik terbesar bersumber dari siklus rantai makanan di dalam perairan. Dekomposisi bahan organik akan menurunkan nilai oksigen terlarut karena bahan organik akan diuraikan oleh mikroorganisme yang mengkonsumsi oksigen yang tersedia. Menurut Effendi (2016), oksigen terlarut dapat berkurang dengan meningkatnya suhu air. Semua hal tersebut menyebabkan nilai DO tidak memenuhi baku mutu yang telah ditetapkan.

\section{Derajat Keasaman $(p H)$}

Konsentrasi $\mathrm{pH}$ yang diperoleh dari hasil analisa yang tertera pada Tabel 1 dan Gambar 2 berada pada kisaran 5,15 - 5,79. Ini merupakan kisaran konsentrasi yang rendah namun mendekati normal untuk tipe perairan sungai. Hasil pengukuran $\mathrm{pH}$ pada Gambar 2 menunjukkan bahwa rerata $\mathrm{pH}$ di lokasi sampling seluruhnya belum memenuhi Baku Mutu Air (BMA) Kelas 2 berdasarkan Peraturan Pemerintah No 22 Tahun 2021, yaitu 6 - 9. Hasil penelitian Dwiyitno et al (2008), di Muara Sungai Barito Kabupaten Barito Kuala berfluktuasi dari dibawah BMA hingga memenuhi baku mutu air, yaitu $4,4-7,6$.

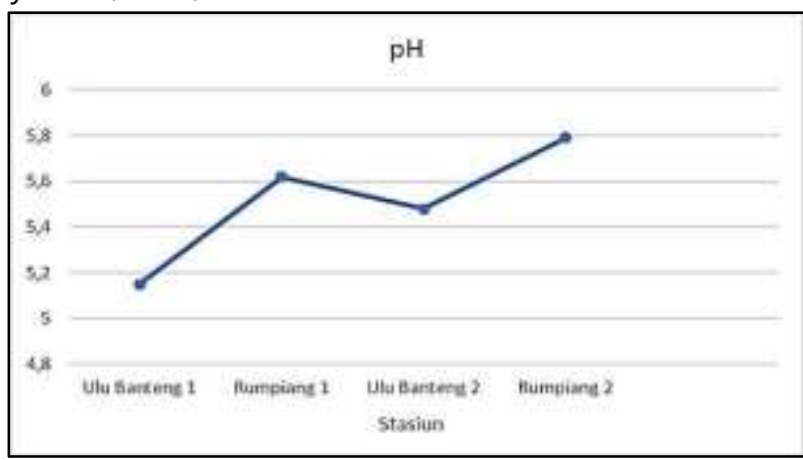

Gambar 2. Nilai pH pada Setiap Stasiun

Pengamatan dari 2 Kali Pengambilan Sampel

Sedangkan hasil penelitian Santoso \& Hidayaturrahmah (2021), yang juga dilakukan di Muara Sungai Barito Kabupaten Barito Kuala, kisaran $\mathrm{pH}$ yang didapatkan memiliki nilai yang memenuhi baku mutu air 6,7-7,1. Tingginya kadar $\mathrm{pH}$ akan menghasilkan kelarutan mineral Fe dan $\mathrm{Zn}$ yang rendah tetapi mineral $\mathrm{Ca}, \mathrm{P}$, dan $\mathrm{Mg}$ yang tinggi (Sofarini et al., 2020). 
Kandungan $\mathrm{pH}$ sangat berpengaruh terhadap tingkat toksisitas beracun, nilai $\mathrm{pH}$ di bawah 5 atau $\mathrm{pH}$ diatas 9 sangat tidak menguntungkan bagi kehidupan makrozoobenthos (Astrini et al., 2014). Taqwa (2010,) menyatakan pH merupakan faktor pembatas bagi organisme yang hidup di suatu perairan. Perairan dengan $\mathrm{pH}$ yang terlalu tinggi atau rendah akan mempengaruhi ketahanan hidup organisme yang hidup di dalamnya (Sofarini et al., 2019).

\section{Biochemical Oxygen Demand (BOD)}

Konsentrasi Biochemical Oxygen Demand (BOD) yang diperoleh dari hasil analisa yang tertera pada Gambar 3 berada pada kisaran 9,01 - 15,32 mg/L. Ini merupakan kisaran nilai BOD yang sangat tinggi, karena BMA maksimal berdasarkan PP No 22 Tahun 20211 untuk Air Sungai (Kelas 2) adalah $3 \mathrm{mg} / \mathrm{l}$. Nilai terendah sudah jauh diatas BMA terdapat di Stasiun Rumpiang sampling 2. Nilai yang tertinggi, jauh diatas batas maksimal nilai BOD, yaitu 15,32 mg/l, berada pada Stasiun Rumpiang sampling 1 dan Stasiun Ulu Banteng sampling 2.

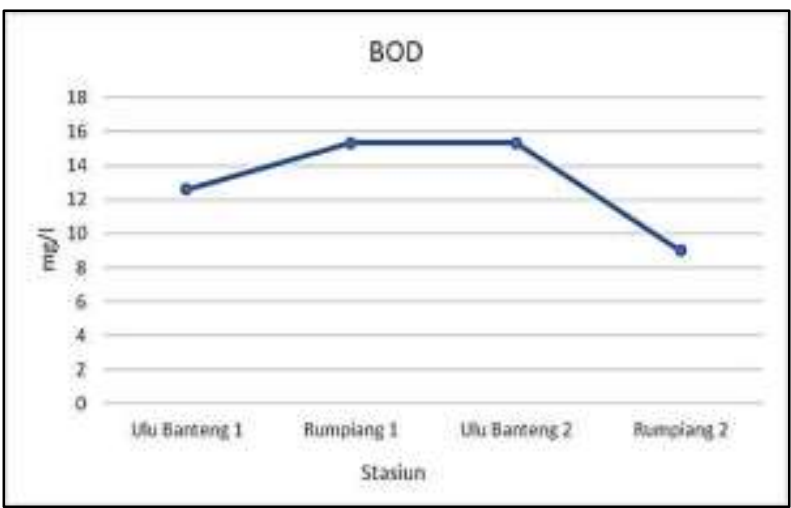

Gambar 3. Nilai BOD pada Setiap Stasiun

Tingginya kadar BOD berhubungan erat dengan rendahnya kadar DO di Sungai Barito, terutama di Stasiun Ulu Banteng sampling 2. Proses dekomposi bahan organik yang banyak bersumber dari dekomposisi bahan organik, dilakukan oleh bakteri aerob yang berperan sebagai dekomposer. Hal ini mnyebabkan kebutuhan oksigen terlarut banyak dimanfaatkan utk aktivitas perombakan bahan organik tersebut. Mekanisme pembusukan material akibat dekomposisi tumbuhan alami dan kontributor total nutrien di badan air seperti limbah cair rumah tangga, pupuk, peternakan dan sistem septik (Arifin et al., 2016) secara berkelanjutan menyebabkan konsentrasi BOD dalam kondisi aerob. Biological Oxygen Demand (BOD) memiliki keterkaitan yang erat dengan nilai DO. Nilai BOD yang tinggi menunjukkan penurunan DO (Waziri \& Ogugbuaja, 2010). Hal ini dapat dipahami karena keberadaan DO di perairan sebagian besar digunakan oleh bakteri dekomposer untuk menguraikan bahan organik di perairan.

\section{Suhu Perairan}

Konsentrasi suhu $\left({ }^{\circ} \mathrm{C}\right)$ yang diperoleh dari hasil analisa yang tertera pada Gambar 4 berada pada kisaran 27,3 - 31,4 mg/l. Ini merupakan kisaran suhu yang normal untuk tipe perairan sungai dataran rendah. Nilai suhu pada penelitian Santoso \& Hidayaturrahmah (2021), di Muara Sungai Barito Kabupaten Barito Kuala mendapatkan kisaran suhu $27-28^{\circ} \mathrm{C}$. Sedangkan dari hasil penelitian Dwiyitno et al. (2008), yang juga dilakukan di Muara Sungai Barito Kabupaten Barito Kuala, kisaran suhu yang doperoleh memiliki nilai yang lebih tinggi, namun masih lebih rendah daril pengukuran suhu pada penelitian kali ini, yaitu $28,5-29,6^{\circ} \mathrm{C}$.

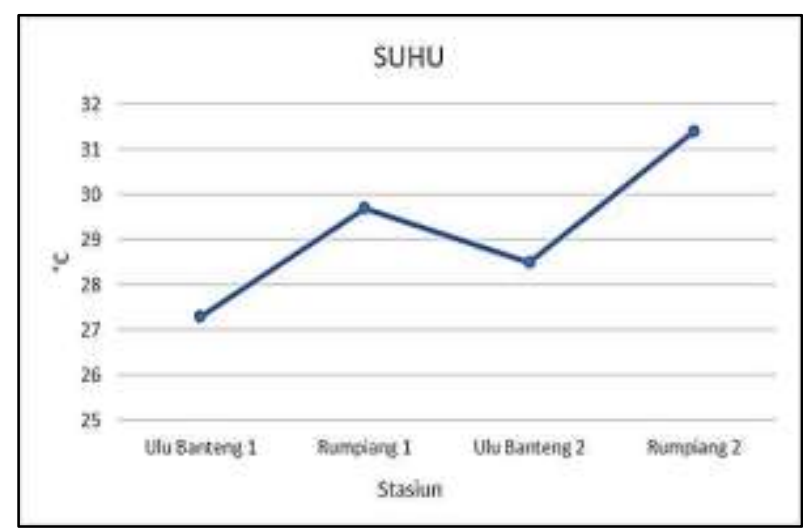

Gambar 4. Nilai Suhu pada Setiap Stasiun

Suhu merupakan parameter fisik yang sangat mempengaruhi pola kehidupan organisme perairan, seperti: distribusi, komposisi, kelimpahan dan mortalitas. Suhu akan menyebabkan kenaikan metabolisme organisme perairan, sehingga kebutuhan oksigen terlarut menjadi meningkat. Menurut (Maresi et al., 2015), suhu merupakan salah satu faktor yang sangat penting dalam mengatur proses kehidupan dan penyebaran organisme. Semakin tinggi suhu semakin tinggi pula derajat kelarutan unsur kimia antara unsur yang satu dengan unsur yang lainnya, sedangkan menurut Effendi (2016), suhu suatu badan air dipengaruhi oleh musim, ketinggian dari 
permukaan dari laut, aliran serta kedalaman air Perubahan suhu berpengaruh terhadap proses fisika, kimia dan biologi yang dialami oleh biota perairan.

\section{Total Suspended Solid}

Konsentrasi Total Suspended Solid (TSS) yang diperoleh dari hasil analisa yang tertera pada Tabel 5 berada pada kisaran $10-40$ mg/L. Nilai tertinggi terdapat di Stasiun Ulu Banteng sampling 1, dan yang terendah pada Stasiun Ulu Banteng sampling 2 (Gambar 5). Secara umum, konsentrasi TSS masih berada pada kisaran normal menurut Baku Mutu Air PP No. 22 Tahun 2021 (Kelas 2), dimana kadar maksimumnya adalah 50 mg/l. Namun pada Stasiun Ulu Banteng sampling 1 terlihat adanya peningkatan konsentrasi TSS. Hal ini menunjukkan adanya penurunan kualitas air di Sungai Barito. Terlihat pada Gambar 8 bahwa konsentrasi TSS tinggi terdapat pada area hulu sungai. Hal ini disebabkan karena pada area tersebut sudah ada aktivitas masyarakat, baik di bidang perikanan atau pengangkutan batubara, sehingga materi padatan tersuspensi dan tidak dapat terlarut. Komponen hidup, seperti eceng gondok yang merupakan partikel TSS juga mempengaruhi nilai konsentrasi air disekitarnya.

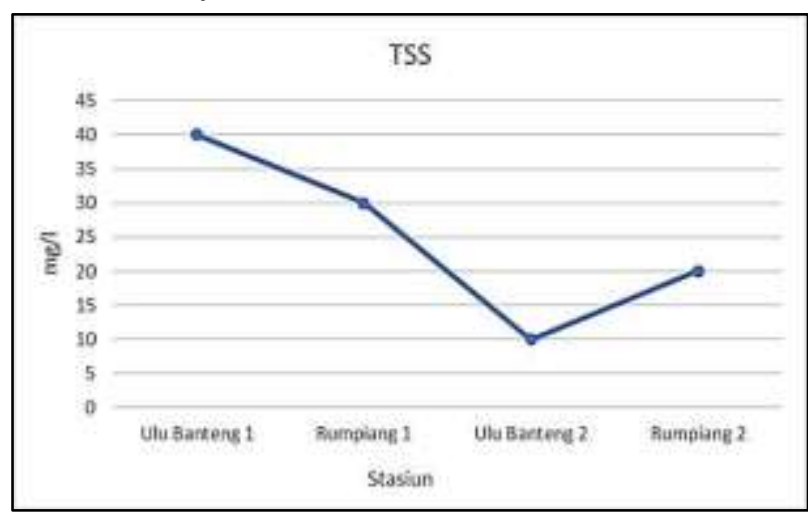

Gambar 5. Nilai Suhu pada Setiap Stasiun

TSS adalah bahan-bahan tersuspensi (diameter $>1 \mu \mathrm{m}$ ) yang tertahan pada saringan miliopore dengan diameter pori 0,45 $\mu \mathrm{m}$. Penyebab TSS di perairan yang utama adalah kikisan tanah atau erosi tanah yang terbawa ke badan air. Konsentrasi TSS apabila terlalu tinggi akan menghambat penetrasi cahaya ke dalam air dan mengakibatkan terganggunya proses fotosintesis (Effendi, 2016).

\section{Kelimpahan Zooplankton}

Zooplankton yang ditemukan di dua lokasi penelitian Sungai Barito selama pengamatan terdiri atas 9 genus yang termasuk kedalam enam filum, yaitu filum Protozoa 2 genus, filum Aschelminthes 1 genus, filum Chaetognatha 2 genus, filum Amoebozoa 1 genus, filum Arthropoda 2 genus dan filum Dinoflagellata 1 genus. Filum Protozoa berjumlah 23,81\%, Aschelminthes 14,29\%, Chaetognatha 33,33\%, Amoebozoa 9,52\%, Arthropoda 14,29\% dan Dinoflagellata 4,75\%.

Beberapa penelitian seringkali menemukan genus zooplankton yang lebih sedikit daripada genus fitoplankton, namun perannya di perairan tidak kalah penting. Zooplankton merupakan konsumen tingkat pertama yang berperan dalam menopang rantai makanan di perairan. Meskipun pergerakannya terbatas dan distribusinya ditentukan oleh keberadaan makanannya, zooplankton berperan dalam menghubungkan produsen utama (fitoplankton) dengan konsumen dalam tingkat makanan lain yang lebih tinggi. Menurut Wahyudiati et al. (2017), dalam rantai makanan, suatu ekosistem perairan peranan zooplankton sebagai konsumen pertama memiliki pengaruh yang cukup penting. Tingginya sebaran konsentrasi plankton di perairan rawa disebabkan oleh tingginya kadar nutrien yang berasal dari limpasan air sungai. Massa air permukaan, sirkulasi, dan region upwelling turut menentukan kesamaan pola sebaran plankton pada skala yang besar (Fernández-Álamo \& Färber-Lorda, 2006).

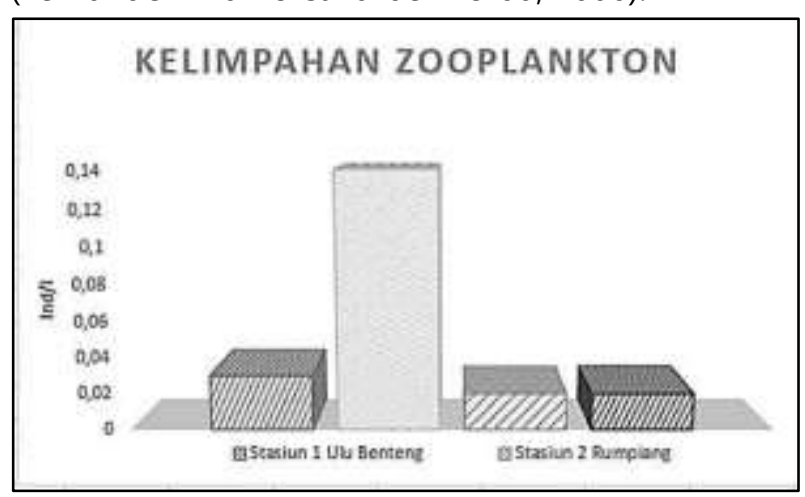

Gambar 6. Kelimpahan Zooplankton (x106 mg/l) di Setiap Stasiun Pengamatan

Rerata kelimpahan zooplankton selama secara spasial di dua stasiun pengamatan adalah 0,085 $\mathrm{x}$ $10^{6}$ ind/I pada Stasiun 1 Ulu Benteng dan 0,02 $\mathrm{x}$ $10^{6}$ ind/l pada Stasiun 2 Rumpiang. Sedangkan kelimpahan temporal selama dua bulan pengamatan adalah $0,025 \times 10^{6}$ ind/I pada Sampling 1 dan 0,08 x 106 ind/l pada sampling 2 . Menurut Reynolds (1987), nilai kelimpahan 
tersebut tergolong dalam kriteria perairan yang kurang subur hingga subur.

Pada Gambar 6 terlihat bahwa secara spasial di setiap stasiun pengamatan, rerata kelimpahan zooplankton tertinggi terjadi di Stasiun 1 Ulu Benteng pada sampling 2 sebesar $0,14 \times 10^{6}$ ind/l dan kelimpahan terendah terjadi di Stasiun 2 Rumpiang baik pada sampling 1 maupun sampling 2, yaitu sebesar $0,02 \times 10^{6}$ ind/l. Untuk genus zooplankton dengan kelimpahan yang tinggi tersebut didominasi oleh genus Sagitta, dimana genus tersebut termasuk dalam filum Chaetognatha. Aliran air Sungai Barito membawa nutrien yang berguna bagi peningkatan kelimpahan zooplankton di stasiun 1 yang berada di kawasan hulu perairan. Hal ini menjadi faktor utama yang menyebabkan kelimpahan zooplankton menjadi tinggi.

Menurut Paterson (2014), faktor-faktor lingkungan seperti suhu air, cahaya, kimiawi air $(\mathrm{pH}$, oksigen, bahan toksik), ketersediaan makanan (fitoplankton, bakteria) dan predasi oleh ikan dan organisme invertebrata) akan mempengaruhi kelimpahan zooplankton. Oleh karena itu, kelimpahan, zooplankton bervariasi bergantung kepada kondisi lingkungan perairannya. Kelimpahan zooplankton yang tinggi pada musim hujan diduga berkaitan erat dengan tingginya kelimpahan fitoplankton.

\section{Indeks Keanekaragaman Zooplankton}

Pada Gambar 7 terlihat bahwa indeks keanekaragaman zooplankton tertinggi pada Stasiun 2 Rumpiang sampling 1 , yaitu sebesar 1,6308 , sedangkan yang terendah pada sampling 2, baik Stasiun 1 Ulu Benteng maupun Stasiun 2 Rumpiang, yaitu 0. Pada sampling 2 pada masingmasing stasiun hanya ditemukan 1 genus saja. Hal inilah yang menyebabkan nilai indeks keanekaragaman menjadi 0 . Kurangnya kesuburan pada saat sampling 2 turut dipengaruhi oleh kondisi cuaca dan aliran nutrien dari arus air sungai. Selain itu, pertumbuhan fitoplankton akan menurunkan pertumbuhan zooplankton karena tekanan spasial dan pemanfaatan fitoplankton sebagai nutrisi untuk zooplankton. Pertumbuhan fitoplankton terjadi pada awal musim hujan ketika air yang baru saja terendam mengandung banyak bahan organik sebagai nutrisi, diikuti oleh pertumbuhan zooplankton yang menggunakan fitoplankton sebagai nutrisi. Perilaku makan zooplankton tersebut memainkan peranan penting dalam proses aliran energi dalam rantai makanan di perairan (Alemany, 2003; Badsi et al., 2010).

\section{INDEKS KEANEKARAGAMAN ZOOPLANKTON}

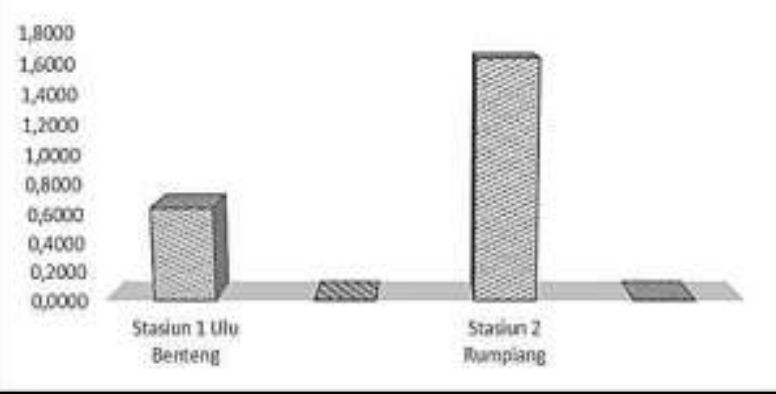

Gambar 7. Indeks Keanekaragaman Zooplankton di Setiap Stasiun Pengamatan

Pada sampling 2 pada masing-masing stasiun hanya ditemukan 1 genus saja. Hal inilah yang menyebabkan nilai indeks keanekaragaman menjadi 0 . Kurangnya kesuburan pada saat sampling 2 turut dipengaruhi oleh kondisi cuaca dan aliran nutrien dari arus air sungai. Selain itu, pertumbuhan fitoplankton dapat menurunkan pertumbuhan zooplankton karena tekanan spasial dan pemanfaatan fitoplankton sebagai nutrisi untuk zooplankton. Pertumbuhan fitoplankton terjadi pada awal musim hujan ketika air yang baru saja terendam mengandung banyak bahan organik sebagai nutrisi, diikuti oleh pertumbuhan zooplankton yang menggunakan fitoplankton sebagai nutrisi. Perilaku makan zooplankton tersebut memainkan peranan penting dalam proses aliran energi dalam rantai makanan di perairan (Alemany, 2003; Badsi et al., 2010).

Distribusi zooplankton yang melimpah di perairan berkaitan erat dengan ketersediaan makanan atau fitoplankton sebagai makanannya. Perubahan komposisi dari komunitas zooplankton bervariasi dari tahun ke tahun dikarenakan perubahan makanan dan lingkungan tempat hidupnya. Fitoplankton adalah sumber pakan alami bagi zooplankton. Dalam suatu ekosistem yang stabil biasanya fitoplankton tersedia dalam jumlah yang melimpah dibandingkan zooplankton sehingga apabila terjadi grazing oleh zooplankton maka keseimbangan ekosistem tetap terkendali. Penurunan kelimpahan fitoplankton sangat drastis apabila kelimpahan zooplankton tinggi yang akan menyebabkan aktivitas grazing zooplankton pun meningkat. Menurut (Saigo et al., 2015), bahwa 
zooplankton dapat merespon kurangnya oksigen terlarut dalam perairan, tingkat nutrien, kontaminasi racun, kualitas makanan yang buruk atau kelimpahan makanan dan keberadaan predator.

\section{Indeks Dominasi Plankton}

Tingginya indeks dominasi zooplankton secara temporal pada sampling 2 di kedua stasiun pada Gambar 8 disebabkan hanya ditemukan 1 genus zooplankton di masing-masing stasiun tersebut. Beberapa genus dari Filum Protozoa dan Chaetognatha disukai ikan sebagai pakan alami (Sofarini et al., 2019). Hasil penelitian ini menyajikan struktur karakteristik perairan sungai dengan dominasi genus Spirostomum dari filum Protozoa dan genus Amoeba dari filum Chaetognatha. Struktur musiman komunitas ini menunjukkan kecenderungan periode transisi untuk beberapa spesies. Populasi Spirostomum dan Amoeba yang diinventarisasi, menjelaskan bahwa kedua genus tersebut dapat dinyatakan sebagai bioindikator lingkungan perairan. (Siswanto et al., 2021; Sofarini et al., 2019)

Dominasi Sagitta secara spasial pada Stasiun 1 Ulu Benteng disebabkan oleh suplai limbah domestik dan kegiatan budidaya Karamba Jaring Apung (KJA) di sekitar lokasi pengamatan. Limbah domestik dan budidaya KJA tersebut tinggi akan kandungan nitrat dan fosfat. Ketersediaan $\mathrm{N}$ dan $\mathrm{P}$ sangat berpengaruh terhadap kehidupan zooplankton, terutama genus Sagitta dari filum Chaetognatha (Kassatkina, 2007) sehingga menyebabkan kondisi perairan menjadi relatif subur.

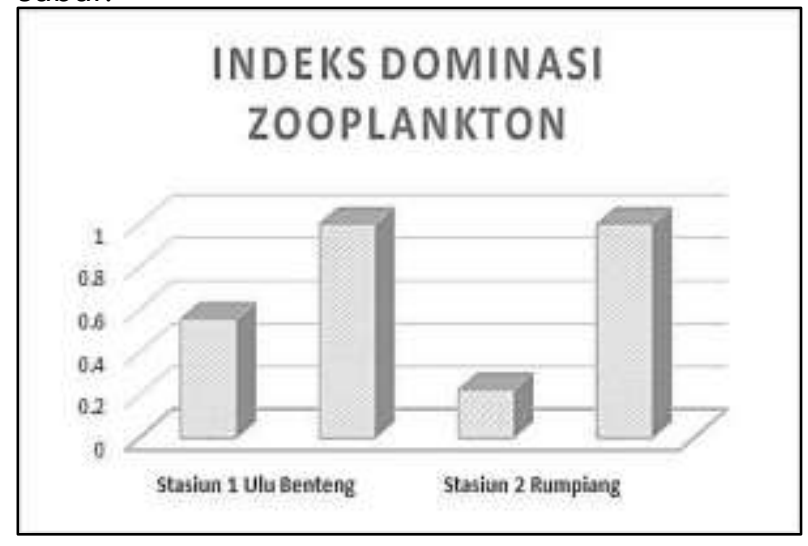

Gambar 8. Indeks Dominansi Zooplankton di Setiap Stasiun Pengamatan

\section{KESIMPULAN}

Berdasarkan hasil pengambilan sampel kualitas air di Stasiun 1 Ulu Benteng pada sampling 1, parameter kunci yang memenuhi Baku Mutu Air PP No 22/2021 untuk Kualitas Air Sungai Kelas 2 adalah TSS, DO dan Suhu. Sedangkan di Stasiun 2 Rumpiang pada sampling 2 adalah TSS, $\mathrm{pH}$ dan suhu. Sedangkan untuk parameter BOD di semua stasiun pada sampling 1 dan 2, semuanya tidak memenuhi Baku Mutu Air PP No 22/2021 untuk Kualitas Air Sungai Kelas 2.

Indeks keanekaragaman zooplankton secara spasial, di Stasiun 1 lebih baik daripada di Stasiun 2, dan ini berhubungan erat dengan parameter kunci kualitas airnya, dimana DO telah memenuhi BMA di Stasiun 1 tapi tidak di Stasiun 2. Sedangkan secara temporal, baik sampling 1 dan sampling 2 memiliki Indeks Keanekaragaman yang rendah.

\section{DAFTAR PUSTAKA}

Peraturan Pemerintah No 22 Tahun 2021 tentang Penyelenggaraan Perlindungan dan Pengelolaan Lingkungan Hidup, 1 Sekretariat Negara Republik Indonesia 483 (2021). http://www.jdih.setjen.kemendagri.go.id/

Alemany, I. A. C. (2003). Condition indices and their relationship with environmental factors in fish larvae. In Departament D'Ecologia Universitat de Barcelona.

Arifin, P., Ardiannor, Sofarini, D., \& Yunandar. (2016). Rapid Assesment Limnologis Sebagai Indikator Pengelolaan (Regulasi dan Pemanfaatan Perairan) di Zona Penyangga Lahan Basah Reservat Danau Panggang Kabupaten Hulu Sungai Utara Kalimantan Selatan. FishScientiae, 6(2), 1-13.

Astrini, A. D. R., Yusuf, M., \& Santoso, A. (2014). Kondisi Perairan Terhadap Struktur Komunitas Makrozoobenthos Di Muara Sungai Karanganyar Dan Tapak, Kecamatan Tugu, Semarang. Journal of Marine Research, 3(1), 2736. https://doi.org/10.14710/jmr.v3i1.4594

Badsi, H., Ali, H. O., Loudiki, M., Hafa, M. El, Chakli, R. and, \& Aamiri, A. (2010). Ecological factors affecting the distribution of zooplankton community in the Massa Lagoon ( Southern Morocco ). African Journal of Environmental Science and Technology, 4(November), 751-762. 
Dwiyitno, Aji, N., \& Indriati, N. (2008). Residu Logam Berat Pada Ikan dan kualitas Lingkungan Perairan Muara Sungai Barito Kalimantan Selatan. Jurnal Pascapanen Dan Bioteknologi Kelautan Dan Perikanan, 3(2), 147-155.

Effendi, H. (2016). River Water Quality Preliminary Rapid Assessment Using Pollution Index. Procedia Environmental Sciences, 33, 562-567. https://doi.org/10.1016/j.proenv.2016.03.108

Fernández-Álamo, M. A., \& Färber-Lorda, J. (2006). Zooplankton and the oceanography of the eastern tropical Pacific: A review. Progress in Oceanography, 69, 318-359. https://doi.org/10.1016/j.pocean.2006.03.003

Hall, E. W. (1985). Review: The New England Quarterly. In The New England Quarterly (Vol. 58, Issue 3, pp. 479-482).

Kassatkina, A. P. (2007). Review of the genera of the family Sagittidae with separation of a new subfamily and description of a new species of the genus Sagitta from the Sea of Japan (Chaetognatha). Zoosystematica Rossica, 16(2), 157-162.

https://doi.org/10.31610/zsr/2007.16.2.157

Maresi, S. R. P., Priyanti, P., \& Yunita, E. (2015). Fitoplankton sebagai Bioindikator Saprobitas Perairan di Situ Bulakan Kota Tangerang. ALKauniyah: Jurnal Biologi, 8(2), 113-122. https://doi.org/10.15408/kauniyah.v8i2.2697

Muhtadi, A. (2017). Produktivitas Primer Perairan. In Researchgate.Net (Vol. 14, Issue 1). https://doi.org/10.13140/RG.2.2.18131.07203

Paterson, M. (2014). Ecological Monitoring and Assessment Network (EMAN) Protocols for Measuring Biodiversity. In Zooplankton in Fresh Waters (Issue January, p. 24).

Rudini, Hidayat, I., \& Ifada, I. I. (2018). Analisis Usaha Pembesaran Ikan Nila (Oreochromis niloticus) di Karamba Jaring Apung Marabahan Kabupaten Barito Kuala. EPrints UNISKA.

Rupawan. (2017). Hasil Tangkapan dan Laju Tangkap Tuguk (Trap Net) di Perairan Muara Sungai Barito Kalimantan Selatan. Fiseries, VI(1), 24-30.

Saigo, M., Zilli, F. L., Marchese, M. R., \& Demonte, D. (2015). Trophic level, food chain length and omnivory in the Paraná River: a food web model approach in a floodplain river system. Ecological Research, 30(5), 843-852. https://doi.org/10.1007/s11284-015-1283-1

Santoso, H. B., \& Hidayaturrahmah, B. S. S. (2021). Aplikasi Biomarker Histopatologi Hati dan Ginjal Ikan Timpakul (Periophthalmodon schlosseri) Sebagai Peringatan Dini Toksisitas Logam Berat Timbal $(\mathrm{Pb})$ di Muara Sungai Barito. Prosiding Seminar Nasional Lingkungan Lahan Basah, 6(3). https://snllb.ulm.ac.id/prosiding/index.php/snll b-lit/article/view/581

Siswanto, S., Sofarini, D., \& Hanifa, M. S. (2021). Kajian Fisika Kimia Perairan Danau Bangkau Sebagai Dasar Pengembangan Budidaya Ikan. Rekayasa, 14(2), 245-251. https://doi.org/10.21107/rekayasa.v14i2.11263

Sofarini, D., Herawati, E. Y., Mahmudi, M., Hertika, A. M. S., Arfiati, D., Musa, M., Amin, M., \& Supriharyono. (2019). Analysis of stomach content of piscivorous fishes caught in danau panggang peatland, South Kalimantan, Indonesia. Biodiversitas, 20(12), 3788-3793. https://doi.org/10.13057/biodiv/d201243

Sofarini, D., Mahmudi, M., Hertika, A. M. S., \& Herawati, E. Y. (2018). Population Dynamic of Head Snake Fish (Channa striata) at Danau Panggang Swamp, South Kalimantan. EnviroScienteae, 14(1), 16.

Sofarini, D., Siswanto, \& Mardiah, A. A. (2020). Eutrophication of Danau Bangkau Peatland Based on Nitrate-Phosphate Concentrations and Fish Diversity. Russian Journal of Agricultural and Socio-Economic Sciences, 11(07), 98-106.

Suprihatin, H. (2014). Penurunan Konsentrasi BOD Limbah Domestik Menggunakan Sistem Wetland dengan Tanaman Hias Bintang Air (Cyperus alternifolius). Dinamika Lingkungan Indonesia, 1(2), 80-87. https://doi.org/10.31258/dli.1.2.p.80-87

Taqwa, A. (2010). Analisis produktivitas primer fitoplankton dan struktur komunitas fauna makrobenthos berdasarkan kerapatan mangrove di kawasan konservasi Kota Tarakan, Kalimantan Timur. In Program Pascasarjana Universitas Diponegoro.

Wahyudiati, N. W. D., Arthana, I. W., \& Kartika, G. R. 
A. (2017). Struktur Komunitas Zooplankton di Bendungan Telaga Tunjung, Kabupaten Tabanan-Bali. Journal of Marine and Aquatic Sciences, 3(1), 115-122. https://doi.org/10.24843/jmas.2017.v3.i01.115122

Wanna, M., Yanto, S., \& Kadirman, K. (2017). Analisis Kualitas Air Dan Cemaran Logam Berat Merkuri $(\mathrm{Hg})$ Dan Timbal (Pb) Pada Ikan Di Kanal Daerah Hertasning Kota Makassar. Jurnal Pendidikan Teknologi Pertanian, 3, S197-S210. https://doi.org/10.26858/jptp.v3i0.5719

Wargasasmita, S. (2005). Ancaman Invasi Ikan
Asing Terhadap Keanekaragaman Ikan Asli. Jurnal Iktiologi Indonesia, 5(1), 5-10. http://jurnaliktiologi.org/index.php/jii/article/view/294

Waziri, M., \& Ogugbuaja, V. O. (2010). Interrelationships between physicochemical water pollution indicators: A case study of River Yobe-Nigeria. American Jouran of Scientific and Industrial Research, 1(1), 76-80. 